\title{
A FUZZY MADM METHOD FOR SOLVING A/R COLLECTION INSTRUMENTS SELECTION PROBLEM
}

Chien-Chang Chou

Department of Shipping Technology, National Kaohsiung Marine University, 482, Chung-Chou 3rd Road, Chi-Chin, Kaohsiung, Taiwan 805, R.O.C., chiench1@ms58.hinet.net

Follow this and additional works at: https://jmstt.ntou.edu.tw/journal

Part of the Business Commons

\section{Recommended Citation}

Chou, Chien-Chang (2007) "A FUZZY MADM METHOD FOR SOLVING A/R COLLECTION INSTRUMENTS SELECTION PROBLEM," Journal of Marine Science and Technology. Vol. 15: Iss. 2, Article 6.

DOI: 10.51400/2709-6998.2039

Available at: https://jmstt.ntou.edu.tw/journal/vol15/iss2/6

This Research Article is brought to you for free and open access by Journal of Marine Science and Technology. It has been accepted for inclusion in Journal of Marine Science and Technology by an authorized editor of Journal of Marine Science and Technology. 


\title{
A FUZZY MADM METHOD FOR SOLVING A/R COLLECTION INSTRUMENTS SELECTION PROBLEM
}

\author{
Chien-Chang Chou*
}

Key words: MADM, fuzzy decision-making, graded mean integration representation, international trade.

The aim of this paper is to propose a ranking method for solving the account receivable $(\mathrm{A} / \mathrm{R})$ collection instrument selection problem in the international trade under the fuzzy multiple attribute decisionmaking (MADM) environment. The representation of multiplication operation on fuzzy numbers is useful for decision makers who are in the fuzzy multiple attribute decision-making environment to rank all candidate $\mathrm{A} / \mathrm{R}$ collection instruments and choose the best one. Based on the graded mean integration representation method, this paper proposes the representation of multiplication operation on fuzzy numbers. Finally this representation of multiplication operation on fuzzy numbers is applied to solving an $\mathrm{A} / \mathrm{R}$ collection instrument selection problem in the international trade. By this representation of multiplication operation on fuzzy numbers, the decision maker can determine quickly the ranking order of all candidate $\mathrm{A} / \mathrm{R}$ collection instruments and then select easily the best one.

\section{INTRODUCTION}

The account receivable (A/R) collection instrument selection is an important issue in the international trade. The selection of a proper A/R collection instrument not only affects the collection behavior of the exporting companies but also the profit potential of banks involved. In general, there are four major alternative instruments for collecting the A/R. The four major alternative instruments include the letter of credit (L/C), telegraphic transfer (T/T), document against payment $(\mathrm{D} / \mathrm{P})$ \& document against acceptance (D/A), and open account $(\mathrm{O} / \mathrm{A})$. The letter of credit has been the preferred instrument in the international trade practice. However, according to the data of the Central Bank of Taiwan, the percentage of the usage of letter of credit (L/C) had declining from $80 \%$ in 1980 to $15 \%$ in 2000. On the other hand, the total percentage of usages of remittance collection instruments including the telegraphic transfer $(\mathrm{T} / \mathrm{T})$ and open account $(\mathrm{O} / \mathrm{A})$ had

Paper Submitted 01/03/06, Accepted 07/05/06. Author for Correspondence: Chien-Chang Chou. E-mail: chiench1@ms58.hinet.net.

*Department of Shipping Technology, National Kaohsiung Marine University, 482, Chung-Chou $3^{\text {rd }}$ Road, Chi-Chin, Kaohsiung, Taiwan 805, R.O.C. increased from $10 \%$ to $80 \%$.

In the past, some precision-based methods for selection the best alternative have been developed. For example, Dahlberg and May [12] utilized the simplex method to determine the optimal location of energy facilities. Tompkins and White [34] introduced a method that used the preference theory to assign weights to subjective factors by making all possible pairwise comparisons between factors. Spohrer and Kmak [30] proposed a weight factor analysis method to integrate the quantitative data and qualitative rating to choose a plant location from numerous alternatives. Stevenson [31] proposed a cost-volume analysis method to select the best plant location. Multiple criteria decision-making methods were provided to deal with the problem of ranking and selecting locations under multiple criteria $[16,27]$. All the methods stated above are based on the concept of accurate measure and crisp evaluation.

In general, the selection of a best $\mathrm{A} / \mathrm{R}$ collection instrument for exporters from two or more alternatives instruments on the basis of two or more factors is a multiple attribute decision-making problem. Under many situations, the values for the qualitative criteria are often imprecisely defined for the decision maker. It is not easy to precisely quantify the rating of each alternative and the precision-based methods as stated above are not adequate to deal with the multiple attribute decision making selection problem $[4,18]$. Since human judgments including preference are often vague and can not estimate his preference with an exact numerical value. A more realistic way may be to use linguistic terms to describe the desired value and important weight of criteria, e.g. "very low", "medium", "high", "fair", "very high", etc $[1,15]$. Due to this type of existing fuzziness in the selection process, fuzzy set theory is an appropriate method for deal with uncertainty and the subjective evaluation data can be more adequately expressed in fuzzy linguistic variables $[4,7$, $18,37]$.

The Analytic Hierarchy Process (AHP) method was first proposed by Satty. The AHP method is a popular technique often used to model subjective deci- 
sion making process based on multiple attribute [28, 29]. Many researchers have used AHP method to deal with decision making problems. Further, the fuzzy concept has also been introduced into the AHP method [2]. Fuzzy AHP method was used to solve fuzzy multiple attribute decision making problems $[8,11,32,33$, $35]$.

The concept of fuzzy sets, which was introduced by Zadeh [37], led to the definition of the fuzzy number and its implementation in fuzzy control and approximate reasoning problems. The basic arithmetic structure for fuzzy numbers were developed by Mizumoto and Tanaka [22, 23], Nahmias [24], Dubois and Prade [13, 14], and Ma et al. [19]. The arithmetic operation was established either by the extension principle [36] or by observing the fuzzy number as a collection of -levels. Chen $[5,6]$ used the Graded Mean Integration Representation method to obtain the representation of one fuzzy number. Based on the Graded Mean Integration Representation method, Chou [9] further proposed the Graded Multiple Integration Representation method to obtain the representation of fuzzy number and then this representation was applied to solving the transportation demand split model for international ports [10]. In this paper, we further propose the representation of multiplication operation on two trapezoidal fuzzy numbers. This representation of multiplication operation on two fuzzy numbers is useful for decision makers who are in the multiple criteria decision making environment to rank all candidate alternatives and choose the best one.

There existed very little literature concerned on the topic of A/R collection instruments selection problem in the international trade under the multiple attribute decision making environment. Therefore, we will propose a fuzzy MADM method for solving the $\mathrm{A} / \mathrm{R}$ collection instrument selection problem.

This paper is organized as follows. We first introduce the Graded Mean Integration Representation method in section 2 . In section 3 we propose the representation of multiplication operation on two trapezoidal fuzzy numbers. Finally, this representation of multiplication operation on two fuzzy numbers is applied to solving a fuzzy MADM A/R collection instrument selection problem in section 4 followed by conclusions in section 5 .

\section{THE GRADED MEAN INTEGRATION REPRESENTATION}

First, we introduce the graded mean integration representation method. In 1998, Chen and Hsieh [6] proposed the graded mean integration representation method based on the integral value of graded mean $h$-level of fuzzy number. Here we describe the meaning as follows. Let $A=(c, a, b, d)$ be a trapezoidal fuzzy number as Figure 1. Suppose the membership function of $A$ is

$$
f_{A}(x)= \begin{cases}\frac{(x-c)}{(a-c)}, & c \leq x \leq a \\ 1, & a \leq x \leq b, \\ \frac{(x-d)}{(b-d)}, & b \leq x \leq d, \\ 0, & \text { otherwise }\end{cases}
$$

$$
\begin{aligned}
& L_{A}(x)=\frac{(x-c)}{(a-c)}, c \leq x \leq a, \\
& L^{-1}{ }_{A}(h)=c+(a-c) h, \quad 0 \leq h \leq 1 . \\
& R_{A}(x)=\frac{(x-d)}{(b-d)}, \quad b \leq x \leq d, \\
& \quad R_{A}^{-1}(h)=d+(b-d) h, \quad 0 \leq h \leq 1 .
\end{aligned}
$$

$L_{A}$ and $R_{A}$ are the functions $L$ and $R$ of the trapezoidal fuzzy number $A$, respectively. $L^{-1}{ }_{A}(h)$ and $R^{-1}{ }_{\mathrm{A}}(h)$ are the inverse functions of the function $L_{A}(x)$ and $R_{A}(x)$ at $h$-level, respectively. Then the graded mean $h$-level value of fuzzy number $A$ is $h\left(L^{-1}(h)+R^{-1}(h)\right) / 2$ as Figure 1. Then the graded mean integration representation of $A$ is

$$
\begin{aligned}
P(A) & =\int_{0}^{1} \frac{h\left(L^{-1}(h)+R^{-1}(h)\right)}{2} d h / \int_{0}^{1} h d h \\
& =\int_{0}^{1} \frac{h(c+(a-c) h+d+(b-d) h)}{2} d h / \int_{0}^{1} h d h \\
& =\frac{1}{6}(c+2 a+2 b+d)
\end{aligned}
$$

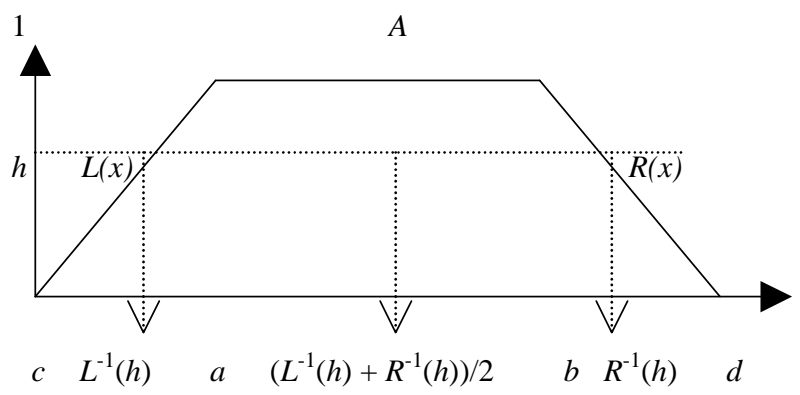

Fig. 1. The graded mean $h$-level of $A$ 


\section{THE REPRESENTATION OF MULTIPLICATION OPERATION ON TWO FUZZY NUMBERS}

Now we define the representation of multiplication operation on two fuzzy numbers as follows.

Definition 1. Let $A_{1}=\left(c_{1}, a_{1}, b_{1}, d_{1}\right)$ and $A_{2}=\left(c_{2}, a_{2}, b_{2}\right.$, $\left.d_{2}\right)$ be two trapezoidal fuzzy numbers. Let $P\left(A_{1} \otimes A_{2}\right)$ be the representation of $A_{1} \otimes A_{2}$.

$$
\begin{aligned}
P & \left(A_{1} \otimes A_{2}\right)=\int_{0}^{1} h\left[\left(\frac{1}{2} L_{A 1}^{-1}(h) \times \frac{1}{2} L_{A 2}^{-1}(h)\right)\right. \\
& +\left(\frac{1}{2} L_{A 1}^{-1}(h) \times \frac{1}{2} R^{-1}{ }_{A 2}(h)\right)+\left(\frac{1}{2} R^{-1}{ }_{A 1}(h) \times \frac{1}{2} L_{A 2}^{-1}(h)\right) \\
& \left.+\left(\frac{1}{2} R^{-1}{ }_{A 1}(h) \times \frac{1}{2} R_{A 2}^{-1}(h)\right)\right] d h / \int_{0}^{1} h d h \\
= & \int_{0}^{1} h\left[\left(\left(c_{1}+\left(a_{1}-c_{1}\right) h\right) / 2 \times\left(c_{2}+\left(a_{2}-c_{2}\right) h\right) / 2\right.\right. \\
& +\left(c_{1}+\left(a_{1}-c_{1}\right) h\right) / 2 \times\left(d_{2}+\left(b_{2}-d_{2}\right) h\right) / 2 \\
& +\left(d_{1}+\left(b_{1}-d_{1}\right) h\right) / 2 \times\left(c_{2}+\left(a_{2}-c_{2}\right) h\right) / 2 \\
& +\left(d_{1}+\left(b_{1}-d_{1}\right) h\right) / 2 \times\left(d_{2}+\left(b_{2}-d_{2}\right) h\right) / 2 d h / \int_{0}^{1} h d h \\
= & \frac{1}{4} \int_{0}^{1}\left[\left(c_{1} c_{2}+c_{1} d_{2}+d_{1} c_{2}+d_{1} d_{2}\right) h\right. \\
& +\left(c_{1} a_{2}-c_{1} c_{2}+c_{2} a_{1}-c_{1} c_{2}+c_{1} b_{2}-c_{1} d_{2}+d_{2} a_{1}-d_{2} c_{1}\right. \\
& \left.+d_{1} a_{2}-d_{1} c_{2}+c_{2} b_{1}-c_{2} d_{1}+d_{1} b_{2}-d_{1} d_{2}+d_{2} b_{1}-d_{1} d_{2}\right) h^{2} \\
& +\left(a_{1} a_{2}-a_{1} c_{2}-c_{1} a_{2}+c_{1} c_{2}+a_{1} b_{2}-a_{1} d_{2}-c_{1} b_{2}+c_{1} d_{2}\right. \\
& \left.+b_{1} a_{2}-b_{1} c_{2}-d_{1} a_{2}+d_{1} c_{2}+b_{1} b_{2}-b_{1} d_{2}-d_{1} b_{2} c_{2}+d_{1} d_{2}\right)+\frac{1}{6}\left[\left(c_{1}+d_{1}\right)\left(a_{2}-c_{2}+b_{2}-d_{2}\right)\right. \\
& \left.+\left(c_{2}+d_{2}\right)\left(a_{1}-c_{1}+b_{1}-d_{1}\right)\right] \\
& +\frac{1}{8}\left[\left(a_{1}-c_{1}+b_{1}\right) h_{1}^{3}\right] / \int_{0}^{1} h d h \\
& \left.\left.d_{1}\right)\left(a_{2}-c_{2}+b_{2}-d_{2}\right)\right] \\
&
\end{aligned}
$$

We have that

$$
\begin{aligned}
& P\left(A_{1} \otimes A_{2}\right)=\frac{1}{4}\left(c_{1} c_{2}+c_{1} d_{2}+d_{1} c_{2}+d_{1} d_{2}\right) \\
& \quad+\frac{1}{6}\left[\left(c_{1}+d_{1}\right)\left(a_{2}-c_{2}+b_{2}-d_{2}\right)+\left(c_{2}+d_{2}\right)\left(a_{1}-c_{1}+b_{1}-d_{1}\right)\right]
\end{aligned}
$$

$$
+\frac{1}{8}\left[\left(a_{1}-c_{1}+b_{1}-d_{1}\right)\left(a_{2}-c_{2}+b_{2}-d_{2}\right)\right]
$$

Now let's see more examples. Let $A_{1}=(1,1,1,1)$ be a real number. $A_{2}=(1,2,3,4)$ is a trapezoidal fuzzy number.

Case $1 A_{1} \otimes A_{1}$

The representation of $A_{1}$ is $P\left(A_{1}\right)=1$. And $P\left(A_{1}\right)$ $\otimes P\left(A_{1}\right)=1 \times 1=1$. On the other hand, by the formula (2) we can obtain that the representation of $A_{1} \otimes A_{1}$ is 1 . We have that $P\left(A_{1}\right) \otimes P\left(A_{1}\right)=1=P\left(A_{1} \otimes A_{1}\right)$.

Case $2 A_{1} \otimes A_{2}$

Similarly, the representations of $A_{1}$ and $A_{2}$ are $P\left(A_{1}\right)=1, P\left(A_{2}\right)=2.5 . P\left(A_{1}\right) \otimes P\left(A_{2}\right)=1 \times 2.5=$ 2.5. By the formula (2), the representation of $A_{1} \otimes A_{2}$ is 2.5. We have that $P\left(A_{1}\right) \otimes P\left(A_{2}\right)=2.5=P\left(A_{1} \otimes A_{2}\right)$.

Case $3 A_{2} \otimes A_{1}$

$P\left(A_{2}\right)=2.5, P\left(A_{1}\right)=1, P\left(A_{2}\right) \otimes P\left(A_{1}\right)=2.5 \times 1$ $=2.5$ is equal to case 2 . That is, $P\left(A_{1}\right) \otimes P\left(A_{2}\right)=P\left(A_{2}\right)$ $\otimes P\left(A_{1}\right)$. On the other hand, by the formula (2), $P\left(A_{2}\right.$ $\left.\otimes A_{1}\right)=2.5$ is also equal to case 2 . That is, $P\left(A_{1} \otimes A_{2}\right)$ $=P\left(A_{2} \otimes A_{1}\right)$. We have that $P\left(A_{2}\right) \otimes P\left(A_{1}\right)=P\left(A_{1}\right) \otimes$ $P\left(\mathrm{~A}_{2}\right)=P\left(A_{2} \otimes A_{1}\right)=P\left(A_{1} \otimes A_{2}\right)$

Case $4 A_{2} \otimes A_{2}$

$P\left(A_{2}\right)=2.5, P\left(A_{2}\right) \otimes P\left(A_{2}\right)=2.5 \times 2.5=6.25$. By the formula (2), $P\left(A_{2} \otimes A_{2}\right)=6.25$. We have that $P\left(A_{2}\right)$ $\otimes P\left(A_{2}\right)=P\left(A_{2} \otimes A_{2}\right)$.

According to the above 4 cases, we note that the representation of multiplication operation on two fuzzy numbers proposed in this paper not only can be used to explain the representation of multiplication operation on fuzzy numbers, but also can be used to explain the representation of multiplication operation on the real numbers.

There are two major differences between the method proposed in this paper and those methods proposed in the past papers. The first difference is that there is only one calculation step involved in the method proposed in this paper. The only one calculation step is that we can directly obtain the representation of multiplication operation on two fuzzy numbers $P\left(A_{2} \otimes A_{2}\right)=$ 6.25 by formula (2) proposed in this paper. There are two calculation steps involved in those methods proposed in the past papers. Step 1 is to calculate the representation of one fuzzy number. Foe example, by those formulas proposed in the past papers, we can obtain the representation of one fuzzy number $P\left(A_{2}\right)=$ 2.5. Step 2 is to further calculate the representation of multiplication operation on two fuzzy numbers by the 
following Eq. (3).

$$
P\left(A_{2}\right) \otimes P\left(A_{2}\right)=2.5 \times 2.5=6.25
$$

Strictly speaking, in the above Eq. (3) $2.5 \times 2.5=$ 6.25 is not a fuzzy arithmetic operation but a mathematic multiplication operation on two real numbers. That is the second major difference between the method proposed in this paper and those methods proposed in the past papers. The method proposed in this paper is a fuzzy arithmetic operation method.

\section{APPLICATION TO A/R COLLECTION INSTRUMEMT SELECTION}

\section{Descriptions of $A / R$ collection instruments}

In general, there are four major alternative instruments for collecting the A/R. The four major alternative instruments include the letter of credit $(\mathrm{L} / \mathrm{C})$, telegraphic transfer $(T / T)$, document against payment $(\mathrm{D} / \mathrm{P})$ and document against acceptance (D/A), and open account $(\mathrm{O} / \mathrm{A})$. The descriptions of the four $\mathrm{A} / \mathrm{R}$ collection instruments are shown as follows.

The letter of credit (L/C) is a common instrument of "payment on shipment" in the international trade. The seller and the buyer agreed to sell and buy goods by $\mathrm{L} / \mathrm{C}$ payment when the international trade contract was made. And then the seller is waiting for shipment until he receives the $\mathrm{L} / \mathrm{C}$ issued by the issuing bank in the buyer's country. The seller has to go to the bank and present the L/C for negotiation after shipment. The negotiation bank must pay the seller money. For the seller, the $\mathrm{L} / \mathrm{C}$ is a protective but expensive and complicated $\mathrm{A} / \mathrm{R}$ collection instrument.

The telegraphic transfer (T/T) is the most popular instrument of "payment" in the international trade. In some cases, the seller and the buyer agreed to sell and buy goods by $\mathrm{T} / \mathrm{T}$ payment in advance when the international trade contract was made. In such situation, the buyer has to go to the bank for telegraphic transfer and forward payment before the seller ships the goods. The $\mathrm{T} / \mathrm{T}$ is the simplest and cheapest collection instrument for the seller. But for the buyer, the $\mathrm{T} / \mathrm{T}$ is not a protective instrument because the $\mathrm{T} / \mathrm{T}$ creates the greatest risk. In some cases, the seller and the buyer agreed to sell and buy goods by $\mathrm{T} / \mathrm{T}$ deferred payment when the international trade contract was made. In such situation, the seller has to export goods and the buyer paid by $\mathrm{T} /$ $\mathrm{T}$ after the goods were shipped.

The document against payment (D/P) and the document against acceptance (D/A) belong to the instruments of "deferred payment" in the international trade. The seller and the buyer agreed to sell and buy goods by
$\mathrm{D} / \mathrm{P}$ or $\mathrm{D} / \mathrm{A}$ payment when the international trade contract was made. The seller must ship the goods. The transportation document will be transmitted through the banking channel to the bank in the buyer's country. The buyer has to go to the bank for document against payment $(\mathrm{D} / \mathrm{P})$ or document against acceptance $(\mathrm{D} / \mathrm{A})$ to receive the transportation document for goods. The D/ $\mathrm{P}$ and $\mathrm{D} / \mathrm{A}$ collection instruments provide a relatively lower secure option than that of the L/C and T/T collection instruments above mentioned. However, The D/P and D/A collection instruments create a relatively lower transaction fee than that of the L/C collection instrument with bank fee typically fixed in $0.5 \%$ of total transaction amount.

The open account $(\mathrm{O} / \mathrm{A})$ is also a kind of "deferred payment" instrument in the international trade. The seller and the buyer agreed to sell and buy goods by $\mathrm{O} /$ A payment when the international trade contract was made. The buyer does not need to forward any payment before the goods be shipped and delivered to the buyer's country. The transportation document will be transmitted directly to the buyer. The transmission of transportation document does not need to transmit through the banking channel. Thus, the O/A collection instrument creates a relatively lowest secure option than the $\mathrm{L} / \mathrm{C}, \mathrm{T} /$ $\mathrm{T}, \mathrm{D} / \mathrm{P}$ and $\mathrm{D} / \mathrm{A}$ collection instruments above mentioned.

The advantages and the disadvantages of the four $\mathrm{A} / \mathrm{R}$ collection instruments are compared and listed in Table 1.

\section{Constructing the MADM hierarchy structure}

An empirical study on A/R collection instrument selection of one hi-tech company which is a computer exporter in the Hsu-Chu Science Park of Taiwan is shown in this section. The evaluation criteria used to selection the $A / R$ collection instrument are from the literature reviews $[3,17,20,21,25,26]$ and consultation with one manager who works for this hi-tech company.

The factors affecting the performance of A/R collection instrument can be classified into 12 criteria including the reduction of the transaction partners' credit risk $\left(C_{1}\right)$, reduction of the interest-rate fluctuation risk $\left(C_{2}\right)$, reduction of the exchange-rate fluctuation risk $\left(C_{3}\right)$, reduction of the political and economic risk in partners' countries $\left(C_{4}\right)$, reduction of transaction fee $\left(C_{5}\right)$, convenience of collection procedure $\left(C_{6}\right)$, time period of collection $\left(C_{7}\right)$, reduction of the collection cost $\left(C_{8}\right)$, help for the seller to expand the market share $\left(C_{9}\right)$, financial structure policy $\left(C_{10}\right), \mathrm{A} / \mathrm{R}$ period policy $\left(C_{11}\right)$, and the collection way of competitors in the same industry $\left(C_{12}\right)$. There are four candidate $\mathrm{A} / \mathrm{R}$ collection instruments including the letter of credit $\left(Y_{1}\right)$, the tele- 
Table 1. The comparision of four $A / R$ collection instruments

\begin{tabular}{|c|c|c|}
\hline Instrument & Advantage & Disadvantage \\
\hline \multirow[t]{4}{*}{$\mathrm{T} / \mathrm{T}$} & 1. The lowest transaction risk for the seller & 1. The highest transaction risk for the buyer \\
\hline & 2. The lowest transaction fee & 2. Helpless for the seller to expand the market share \\
\hline & 3. The shortest collection time & \\
\hline & 4. Financial facility $100 \%$ & \\
\hline \multirow[t]{4}{*}{$\mathrm{L} / \mathrm{C}$} & 1. Lower transaction risk for the seller & 1. The highest transaction fee (banking fee) \\
\hline & 2. Shorter collection time of sight $\mathrm{L} / \mathrm{C}$ & 2. The issuing bank takes a risk of non-performance of the buyer \\
\hline & 3. Financial facility $70 \% \sim 90 \%$ & 3. Longer collection time of usance $\mathrm{L} / \mathrm{C}$ \\
\hline & & 4. Helpless for the seller to expand the market share \\
\hline \multirow[t]{3}{*}{$\mathrm{D} / \mathrm{P}, \mathrm{D} / \mathrm{A}$} & 1. Low risk for the buyer & 1. High risk for the seller \\
\hline & 2. Financial facility $50 \% \sim 70 \%$ & 2. Longer collection time than that of $\mathrm{L} / \mathrm{C}$ \\
\hline & 3. Helpful for sellers to expand market shares & \\
\hline \multirow[t]{3}{*}{$\mathrm{O} / \mathrm{A}$} & 1. The lowest risk for the buyer & 1. The highest risk for the seller \\
\hline & 2. The lowest transaction fee & 2. The highest $\mathrm{A} / \mathrm{R}$ management cost for the seller \\
\hline & 3. Helpful for sellers to expand market shares & 3. Longer collection time \\
\hline
\end{tabular}

Table 2. Linguistic variables for importance weight of criteria

\begin{tabular}{ll}
\hline Very low & $(0.3,0.35,0.45,0.5)$ \\
Low & $(0.4,0.45,0.55,0.6)$ \\
Medium low & $(0.5,0.55,0.65,0.7)$ \\
Fair & $(0.6,0.65,0.75,0.8)$ \\
Medium high & $(0.7,0.75,0.85,0.9)$ \\
High & $(0.8,0.85,0.95,1.0)$ \\
Very high & $(1.0,1.0,1.0,1.0)$ \\
\hline
\end{tabular}

graphic transfer $\left(Y_{2}\right)$, the document against payment or document against acceptance $\left(Y_{3}\right)$, and the open account $\left(Y_{4}\right)$ for evaluation in this decision making selection problem. The decision-making hierarchical structure of this $A / R$ collection instrument selection problem is shown as Figure 2.

\section{Solution procedure}

The proposed representation of multiplication operation on two fuzzy numbers in this paper is currently applied to solving this A/R collection instrument selection problem. The computational procedure is summarized as follows.

Step 1. The decision maker uses the linguistic weighting variables shown in Table 2 to assess the importance of criteria and present it in Table 3.

Step 2. The decision maker uses the linguistic rating variables shown in Table 4 to evaluate the rating of candidate alternatives with respect to each criteria and present it in Table 5 .

Step 3. Calculate the total rating of each candidate instrument. Assume there are $N$ candidate instruments
Table 3. The importance weight of each criteria

\begin{tabular}{lll}
\hline$C_{1}$ & Very high & $(1.0,1.0,1.0,1.0)$ \\
$C_{2}$ & Very low & $(0.3,0.35,0.45,0.5)$ \\
$C_{3}$ & Medium high & $(0.7,0.75,0.85,0.9)$ \\
$C_{4}$ & Very low & $(0.3,0.35,0.45,0.5)$ \\
$C_{5}$ & Very low & $(0.3,0.35,0.45,0.5)$ \\
$C_{6}$ & Very low & $(0.3,0.35,0.45,0.5)$ \\
$C_{7}$ & Very high & $(1.0,1.0,1.0,1.0)$ \\
$C_{8}$ & Medium high & $(0.7,0.75,0.85,0.9)$ \\
$C_{9}$ & High & $(0.8,0.85,0.95,1.0)$ \\
$C_{10}$ & Medium high & $(0.7,0.75,0.85,0.9)$ \\
$C_{11}$ & High & $(0.8,0.85,0.95,1.0)$ \\
$C_{12}$ & Medium high & $(0.7,0.75,0.85,0.9)$ \\
\hline
\end{tabular}

Table 4. Linguistic variables for preference of each alternative

\begin{tabular}{ll}
\hline Very poor & $(2.0,2,5,3.5,4.0)$ \\
Poor & $(3.0,3.5,4.5,5.0)$ \\
Medium poor & $(4.0,4.5,5.5,6.0)$ \\
Fair & $(5.0,5.5,6.5,7.0)$ \\
Medium good & $(6.0,6.5,7.5,8.0)$ \\
Good & $(7.0,7.5,8.5,9.0)$ \\
Very good & $(8.0,8.5,9.5,10)$ \\
\hline
\end{tabular}

$\left(Y_{1}, Y_{2}, Y_{n} \ldots, Y_{N}\right)$, I evaluation criteria $\left(C_{1}, C_{2}, C_{i} \ldots, C_{I}\right)$. Let $P_{(Y n, C i)}$ be the fuzzy rating assigned to the $n^{\text {th }}$ candidate instrument by the decision maker under criteria $C_{i}$. And $W_{i}$ is the importance weights of $C_{i}$. Let $P_{n i}$ $=P\left(W_{i} \otimes P_{(Y n, C i)}\right)$ be the representation of $W_{i} \otimes P_{(Y n, C i)}$, where $1 \leq n \leq N, 1 \leq i \leq I$. And let $T P_{n}=\sum_{i=1}^{I} P_{n i}$ be the 
Goal

Criteria

Alternative

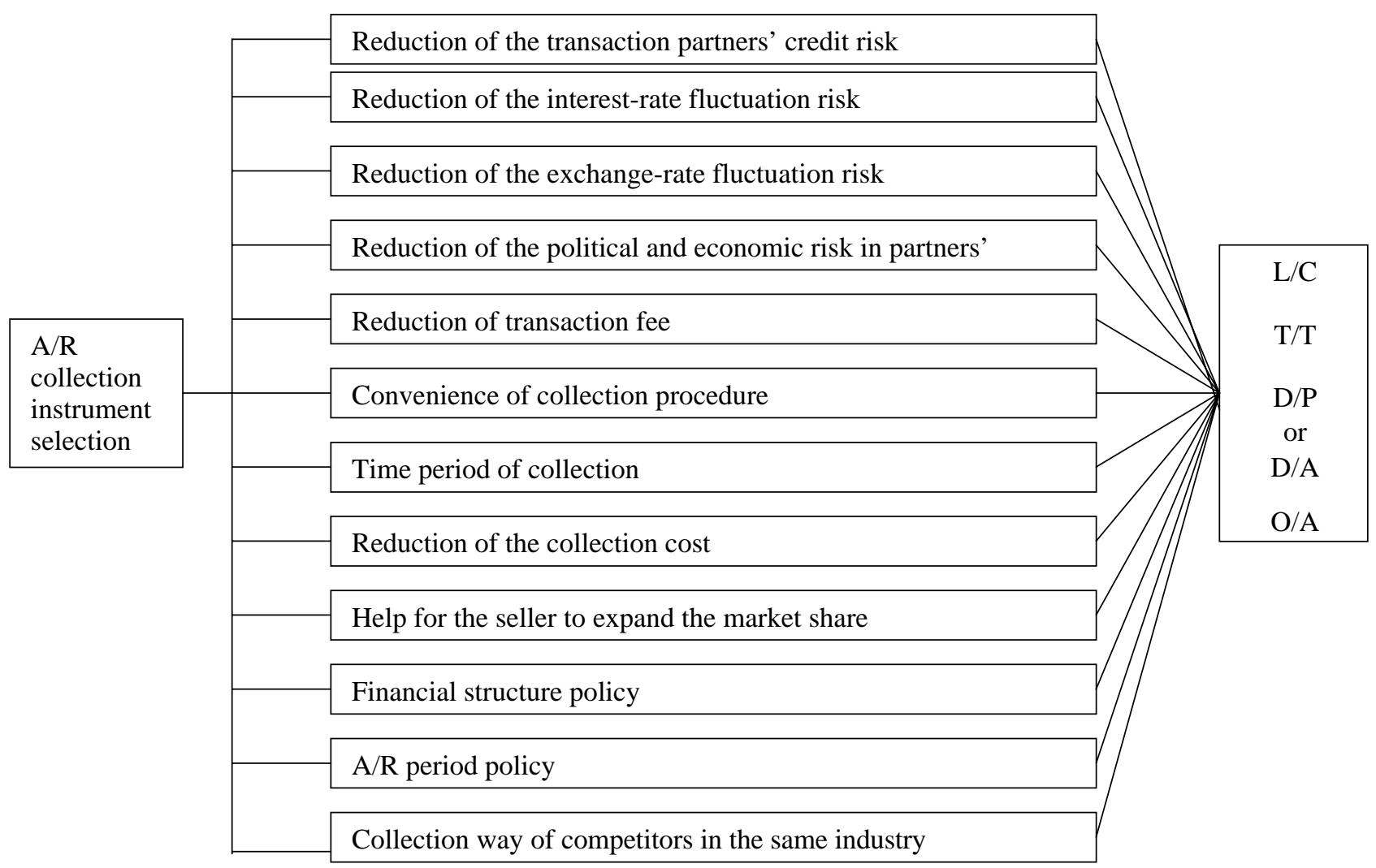

Fig. 2. The decision-making hierarchy structure of $A / R$ collection instrument selection.

total fuzzy rating of the $n^{\text {th }}$ candidate instrument. For example, the total rating of candidate instrument $Y_{1}$ is

$$
\begin{aligned}
& T P_{1}=\sum_{i=1}^{I} P_{1 i}=\sum_{i=1}^{I} P\left(W_{i} \otimes P_{(Y 1, C i)}\right) \\
= & (1.0,1.0,1.0,1.0) \otimes(6.0,6,5,7,5,8.0) \\
& +(0.3,0.35,0.45,0.5) \otimes(5.0,5.5,6.5,7.0) \\
& +(0.7,0.75,0.85,0.9) \otimes(5.0,5.5,6.5,7.0) \\
& +(0.3,0.35,0.45,0.5) \otimes(5.0,5.5,6.5,7.0) \\
& +(0.3,0.35,0.45,0.5) \otimes(2.0,2,5,3.5,4.0) \\
& +(0.3,0.35,0.45,0.5) \otimes(3.0,3.5,4.5,5.0) \\
& +(1.0,1.0,1.0,1.0) \otimes(5.0,5.5,6.5,7.0) \\
& +(0.7,0.75,0.85,0.9) \otimes(4.0,4.5,5.5,6.0) \\
& +(0.8,0.85,0.95,1.0) \otimes(2.0,2,5,3.5,4.0) \\
& +(0.7,0.75,0.85,0.9) \otimes(2.0,2,5,3.5,4.0) \\
& +(0.8,0.85,0.95,1.0) \otimes(2.0,2,5,3.5,4.0) \\
& +(0.7,0.75,0.85,0.9) \otimes(2.0,2,5,3.5,4.0)]
\end{aligned}
$$

Then according to the representation of multiplication operation on two fuzzy numbers proposed in this paper

$$
\begin{aligned}
& P\left(A_{1} \otimes A_{2}\right)=\frac{1}{4}\left(c_{1} c_{2}+c_{1} d_{2}+d_{1} c_{2}+d_{1} d_{2}\right) \\
& +\frac{1}{6}\left[\left(c_{1}+d_{1}\right)\left(a_{2}-c_{2}+b_{2}-d_{2}\right)+\left(c_{2}+d_{2}\right)\left(a_{1}-c_{1}+\right.\right. \\
& \left.\left.\quad b_{1}-d_{1}\right)\right]+\frac{1}{8}\left[\left(a_{1}-c_{1}+b_{1}-d_{1}\right)\left(a_{2}-c_{2}+b_{2}-d_{2}\right)\right]
\end{aligned}
$$

The decision maker can obtain quickly the total rating of candidate instrument $Y_{1} . T P_{1}=7+2.4+4.8+$ $2.4+1.2+1.6+6.0+4.0+2.7+2.4+2.7+2.4=$ 39.6 .

Similarly, we can obtain easily the total rating $T P_{2}$ $=61.7$ for candidate instrument $Y_{2}$, the total rating $T P_{3}$ $=31.9$ for candidate instrument $Y_{3}$ and the total rating $T P_{4}=41.7$ for candidate instrument $Y_{4}$. Thus the decision maker of computer company can rank quickly all candidate collection instruments, $T P_{2}=61.7>T P_{4}=$ $41.7>T P_{1}=39.6>T P_{2}=31.9$, and then select easily the candidate instrument $Y_{2}$ (telegraphic transfer, T/T) as the best collection instrument. 
Table 5. The rating of each candidate alternative with respect to each criteria

\begin{tabular}{|c|c|c|}
\hline \multirow[t]{4}{*}{$C_{1}$} & $Y_{1}$ & $(6.0,6.5,7.5,8.0)$ \\
\hline & $Y_{2}$ & $(8.0,8.5,9.5,10)$ \\
\hline & $Y_{3}$ & $(3.0,3.5,4.5,5.0)$ \\
\hline & $Y_{4}$ & $(2.0,2,5,3.5,4.0)$ \\
\hline \multirow[t]{4}{*}{$C_{2}$} & $Y_{1}$ & $(5.0,5.5,6.5,7.0)$ \\
\hline & $Y_{2}$ & $(8.0,8.5,9.5,10)$ \\
\hline & $Y_{3}$ & $(3.0,3.5,4.5,5.0)$ \\
\hline & $Y_{4}$ & $(2.0,2,5,3.5,4.0)$ \\
\hline \multirow[t]{4}{*}{$C_{3}$} & $Y_{1}$ & $(5.0,5.5,6.5,7.0)$ \\
\hline & $Y_{2}$ & $(8.0,8.5,9.5,10)$ \\
\hline & $Y_{3}$ & $(3.0,3.5,4.5,5.0)$ \\
\hline & $Y_{4}$ & $(2.0,2,5,3.5,4.0)$ \\
\hline \multirow[t]{4}{*}{$C_{4}$} & $Y_{1}$ & $(5.0,5.5,6.5,7.0)$ \\
\hline & $Y_{2}$ & $(8.0,8.5,9.5,10)$ \\
\hline & $Y_{3}$ & $(3.0,3.5,4.5,5.0)$ \\
\hline & $Y_{4}$ & $(2.0,2,5,3.5,4.0)$ \\
\hline \multirow[t]{4}{*}{$C_{5}$} & $Y_{1}$ & $(2.0,2,5,3.5,4.0)$ \\
\hline & $Y_{2}$ & $(7.0,7.5,8.5,9.0)$ \\
\hline & $Y_{3}$ & $(3.0,3.5,4.5,5.0)$ \\
\hline & $Y_{4}$ & $(7.0,7.5,8.5,9.0)$ \\
\hline \multirow[t]{4}{*}{$C_{6}$} & $Y_{1}$ & $(3.0,3.5,4.5,5.0)$ \\
\hline & $Y_{2}$ & $(8.0,8.5,9.5,10)$ \\
\hline & $Y_{3}$ & $(3.0,3.5,4.5,5.0)$ \\
\hline & $Y_{4}$ & $(7.0,7.5,8.5,9.0)$ \\
\hline \multirow[t]{4}{*}{$C_{7}$} & $Y_{1}$ & $(5.0,5.5,6.5,7.0)$ \\
\hline & $Y_{2}$ & $(8.0,8.5,9.5,10)$ \\
\hline & $Y_{3}$ & $(3.0,3.5,4.5,5.0)$ \\
\hline & $Y_{4}$ & $(2.0,2,5,3.5,4.0)$ \\
\hline \multirow[t]{4}{*}{$C_{8}$} & $Y_{1}$ & $(4.0,4.5,5.5,6.0)$ \\
\hline & $Y_{2}$ & $(8.0,8.5,9.5,10)$ \\
\hline & $Y_{3}$ & $(3.0,3.5,4.5,5.0)$ \\
\hline & $Y_{4}$ & $(3.0,3.5,4.5,5.0)$ \\
\hline \multirow[t]{4}{*}{$C_{9}$} & $Y_{1}$ & $(2.0,2,5,3.5,4.0)$ \\
\hline & $Y_{2}$ & $(2.0,2,5,3.5,4.0)$ \\
\hline & $Y_{3}$ & $(2.0,2,5,3.5,4.0)$ \\
\hline & $Y_{4}$ & $(8.0,8.5,9.5,10)$ \\
\hline \multirow[t]{4}{*}{$C_{10}$} & $Y_{1}$ & $(2.0,2,5,3.5,4.0)$ \\
\hline & $Y_{2}$ & $(5.0,5.5,6.5,7.0)$ \\
\hline & $Y_{3}$ & $(2.0,2,5,3.5,4.0)$ \\
\hline & $Y_{4}$ & $(2.0,2,5,3.5,4.0)$ \\
\hline \multirow[t]{4}{*}{$C_{11}$} & $Y_{1}$ & $(2.0,2,5,3.5,4.0)$ \\
\hline & $Y_{2}$ & $(5.0,5.5,6.5,7.0)$ \\
\hline & $Y_{3}$ & $(3.0,3.5,4.5,5.0)$ \\
\hline & $Y_{4}$ & $(3.0,3.5,4.5,5.0)$ \\
\hline \multirow[t]{4}{*}{$C_{12}$} & $Y_{1}$ & $(2.0,2,5,3.5,4.0)$ \\
\hline & $Y_{2}$ & $(2.0,2,5,3.5,4.0)$ \\
\hline & $Y_{3}$ & $(2.0,2,5,3.5,4.0)$ \\
\hline & $Y_{4}$ & $(8.0,8.5,9.5,10)$ \\
\hline
\end{tabular}

\section{CONCLUSION}

The representation of multiplication operation on two fuzzy numbers is useful for decision makers who are in the fuzzy multiple attribute decision-making environment to rank all candidate alternatives and choose the best one. In this paper, we propose the representation of multiplication operation on two fuzzy numbers and then this representation is applied to an A/R collection instrument selection problem in the international trade. Based on this representation of multiplication operation on two fuzzy numbers, decision makers can rank quickly the rank ordering of all alternatives and then choose easily the best one in the fuzzy multiple attribute decision making environment. This representation of multiplication operation on two fuzzy numbers proposed in this paper not only can be applied to solving the $\mathrm{A} / \mathrm{R}$ collection instrument selection problem in the international trade but also can be applied to solving other fuzzy multiple attribute decision-making problems.

\section{REFERENCES}

1. Bellman, R.E. and Zadeh, L.A., "Decision-Making in a Fuzzy Environment," Management Science, Vol. 17, No. 4, pp. 141-164 (1970).

2. Buckley, J.J., "Ranking Alternatives using Fuzzy Numbers," Fuzzy Sets and Systems, Vol. 15, No. 1, pp. 21-31 (1985).

3. Callahan, W.T., "Understanding Commercial Factoring and Credit Insurance," Collections \& Credit Risk, Vol. 5, No. 6, pp. 56-58 (2000).

4. Chen, C.T., "A Fuzzy MCDM Method Based on Interval Analysis for Solving Plant Location Selection Problem," Journal of the Chinese Institute of Industrial Engineers, Vol. 17, No. 1, pp. 111-120 (2000).

5. Chen, S.H., "Operations of Fuzzy Numbers with Step form Membership Function using Function Principle," Information Sciences, Vol. 108, pp. 149-155 (1998).

6. Chen, S.H. and Hsieh, C.H., "Graded Mean Integration Representation of Generalized Fuzzy Number, Proceeding of 1998 Sixth Conference on Fuzzy Theory and Its Application (CD-ROM), Chinese Fuzzy Systems Association, Taiwan, R.O.C., pp. 1-6 (1998).

7. Chen, S.J. and Hwang, C.L., "Fuzzy Multiple Attribute Decision Making: Methods and Applications," SpringVerlag, Berlin (1992).

8. Chiou, H.K. and Tzeng, G.H., "Fuzzy Multiple Criteria Decision Making Approach for Industrial Green Engineering," Environment Management, Vol. 30, No. 6, pp. 816-830 (2002).

9. Chou, C.C., "The Canonical Representation of Multiplication Operation on Triangular Fuzzy Numbers," International Journal of Computers and Mathematics with 
Applications, Vol. 45, pp. 1601-1610 (2003).

10. Chou, C.C., Chu, C.W., and Liang, G.S., "A Transportation Demand Split Model for International Ports," International Journal of the Eastern Asia Society for Transportation Studies, Vol. 5, pp. 625-637 (2003).

11. Chou, T.Y. and Liang, G.S., "Application of a Fuzzy Multiple-Criteria Decision-Making Model for Shipping Performance Evaluation," Maritime Policy and Management, Vol. 28, No. 4, pp. 375-392 (2001).

12. Dahlberg, M.D. and May, J.H., "Linear Programming for Sitting of Energy Facilities," Journal of Energy Engineering, pp. 5-14 (1980).

13. Dubois, D. and Prade, H., "Operations on Fuzzy Numbers," Journal of Systems Science, Vol. 9, pp. 613-626 (1978).

14. Dubois, D. and Prade, H., "Fuzzy Number: an Overview, in Bezdek, J.C. (Ed.), The Analysis of Fuzzy Information, Vol. 1: Mathematics, CRC Press, Boca Raton, FL, pp. 339 (1987).

15. Hsu, H.M. and Chen, C.T., "Fuzzy Credibility Relation Method for Multiple Criteria Decision-Making Problems," Information Sciences, Vol. 96, pp. 79-91 (1997).

16. Hwang, C.L. and Yoon, K., Multiple Attributes Decision Making Methods and Applications, Springer-Verlag, Berlin (1981).

17. Jamal, A.M., Bhaba, R., and Wang, S., "Optimal Payment Time for a Retailer under Remitted Delay for Payment by the Wholesaler," International Journal of Production Economics, Vol. 66, No. 1, pp. 59-66 (2000).

18. Liang, G.S. and Wang, M.J., "A Fuzzy Multiple Criteria Decision-Making Method for Facilities Site Selection," International Journal of Production Research, Vol. 29, No. 11, pp. 2313-2330 (1991).

19. Ma, M., Friedman, M., and Kandel, A., “A New Fuzzy Arithmetic," Fuzzy Sets and Systems, Vol. 108, pp. 83-90 (1999).

20. Mann, R.J. and Gillette, C.P., "The role of Letter of Credit in Payment Transactions," Michgan Law Review, Vol. 98, No. 8, pp. 2494-2497 (2000).

21. Mehta, R., "Export Letter of Credit: Eight Steps to Errors-Free Compliance," International Trade Forum, Vol. 4, pp. 12-15 (1999).

22. Mizumoto, M. and Tanaka, K., "The four Operations of Arithmetic on Fuzzy Numbers," Systems Computer and Controls, Vol. 7, No. 5, pp. 73-81 (1976).

23. Mizumoto, M. and Tanaka, K., "Some Properties of
Fuzzy Numbers," in Gupta, M.M., Ragade, R.K., and Yager, R.R. (Eds), Advances in Fuzzy Set Theory and Applications, Amsterdam Bublishing, North-Holland, pp. 156-164 (1979).

24. Nahmias, S., "Fuzzy Variables," Fuzzy Sets and Systems, Vol. 1, pp. 97-111 (1978).

25. Pereira, R., "International Factoring," World Trade, Vol. 12, No. 12, pp. 68-69 (1999).

26. Rahardjo, K., "Collateral Products: Not Just Letter of Credit," Risk Management, Vol. 46, No. 3, pp. 36-38 (1999).

27. Rietveld, P. and Ouwersloot, H., "Ordinal Data in Multicriteria Decision Making, a Stochastic Dominance Approach to Sitting Nuclear Power Plants," European Journal of Operation Research, Vol. 56, pp. 249-262 (1992).

28. Saaty, T.L., "A Scaling Method for Priorities in Hierarchical Structure," Journal of Mathematical Psychology, Vol. 15, No. 2, pp. 274-281 (1977).

29. Saaty, T.L., The Analytic Hierarchy Process, McGrawHill Inc., New York (1980).

30. Spohrer, G.A. and Kmak, T.R., "Qualitative Analysis used in Evaluating Alternative Plant Location Scenarios," Industrial Engineering, August, pp. 52-56 (1984).

31. Stevenson, W.J., Production/Operation Management, Irwin Inc., IL (1993).

32. Tang, M.T., Tzeng, G.H., and Wang, S.W., "A Hierarchy Fuzzy MCDM Method for Studying Electronic Marketing Strategies in the Information Service Industry," Journal of International Information Management, Vol. 8, No. 1, pp. 1-22 (1999).

33. Teng, J.Y. and Tzeng, G.H., "Fuzzy Multiple-Criteria Ranking of Urban Transportation Investment Alternative," Transportation Planning and Technology, Vol. 20, No. 1, pp. 15-31 (1996).

34. Tompkins, J.A. and White, J.A., Facilities Planning, John Wiley \& Sons, New York (1984).

35. Tsaur, S.H., Chang, T.Y., and Yen, C.H., "The Evaluation of Airline Service Quality by Fuzzy MCDM," Tourism Management, Vol. 23, pp. 107-115 (2002).

36. Zadeh, L.A., "Fuzzy Sets," Information and Control, Vol. 8, pp. 338-353 (1965).

37. Zadeh, L.A., "The concept of a Linguistic Variable and Its Application to Approximate Reasoning," Information Sciences, Vol. 8, pp. 199-249 (1975). 